\title{
Patient age and cutaneous malignant melanoma: Elderly patients are likely to have more aggressive histological features and poorer survival
}

\author{
FARUK TAS and KAYHAN ERTURK \\ Department of Medical Oncology, Institute of Oncology, Istanbul University, Istanbul 34390, Turkey
}

Received April 14, 2017; Accepted September 28, 2017

DOI: $10.3892 / \mathrm{mco} .2017 .1439$

\begin{abstract}
Patient age has been reported as a highly significant and strong predictor of the outcome in patients with cutaneous melanoma. The aim of the present study was to determine the clinical significance of patient age in Turkish patients with cutaneous melanoma. A total of 1,169 patients with pathologically proven cutaneous melanoma were enrolled. Age of patients was classified as young ( $<40$ years), middle-aged ( $40-59$ years) and old ( $\geq 60$ years). The median age of the patients was 51 years (range, 16-104 years). Non-superficial spreading histology was significantly more observed in old patients than in the other age groups $(\mathrm{P}<0.001)$. A lower Clark invasion level was significantly more observed in young patients compared with the other age groups $(\mathrm{P}=0.013)$ and higher levels were significantly more observed in older patients compared with the other age groups $(\mathrm{P}=0.002)$. Furthermore, the rate of thin Breslow depth was significantly higher in young patients compared with others $(\mathrm{P}=0.038)$. Although a lower mitotic rate was observed predominantly in young patients compared with others $(\mathrm{P}=0.007)$, ulceration was significantly more present in older patients $(\mathrm{P}<0.001)$ and absent in the young patients $(\mathrm{P}=0.003)$. Patient age was not significantly associated with relapse-free survival $(\mathrm{P}=0.327)$, whereas a significant correlation was demonstrated for overall survival (OS) $(\mathrm{P}=0.007)$. The old patients had poorer survival compared with the other ages $(\mathrm{P}=0.009$ for young patients and $\mathrm{P}=0.012$ for middle-aged patients). However, patient age did not remain significant for OS in multivariate analysis $(\mathrm{P}=0.768)$. In conclusion, although patient age does not have a significant predictive role on nodal involvement, recurrence and metastasis, an age of $\geq 60$ years may be associated with more aggressive histological features and poorer outcome in patients with cutaneous melanoma.
\end{abstract}

Correspondence to: Dr Faruk Tas, Department of Medical Oncology, Institute of Oncology, Istanbul University, 118 Millet Street, Capa, Istanbul 34390, Turkey

E-mail: faruktas2002@yahoo.com

Key words: age, older, melanoma, patient, prognostic, survival

\section{Introduction}

Cutaneous melanoma is the most lethal skin cancer in the world and is the fifth (6\%) and sixth (4\%) most common type of cancer in men and women, respectively, in the US (1). In 2017, 87,110 patients may be diagnosed with melanoma and $\sim 9,730$ patients may lose their lives as a result of this in the US (1). The incidence of melanoma continues to increase dramatically; the lifetime risk of developing melanoma is 1 in 28 for men and 1 in 44 women. It is increasing in men more rapidly than any other tumor and in women more rapidly than any other malignancy, except for lung carcinoma. The outcome of melanoma depends on the stage at presentation $(2,3)$. For patients with localized melanomas, survival rates also depend on regional nodal involvement, tumor thickness, ulceration and mitotic rate $(2,3)$.

The impact of patient age has been reported as a highly significant and strong predictor of outcome in patients with cutaneous melanoma (3-9). Elderly patients with melanoma have been associated with a higher mortality rate than other age groups because they had the most aggressive prognostic features of the primary melanomas, including thicker depth, higher mitotic rates and increased likelihood of ulceration (3-6). However, notably, this detrimental outcome occurred although these patients had a lower rate of lymph node metastasis compared with the other age groups in the investigations (4,6-9). Thus, melanomas in patients of different ages, among older and younger patients, have different biological characteristics in large datasets (3-6).

The present study utilized a large group of patients from a single institution and aimed to demonstrate how patient age affected the presentation and outcome of cutaneous melanoma.

\section{Patients and methods}

Patients. Between January 1993 and December 2015, 1,169 adult patients $\geq 16$ years of age (male:female ratio, $1: 19$ ) with histologically confirmed cutaneous melanoma admitted to the Institute of Oncology, Istanbul University (Istanbul, Turkey), were investigated retrospectively. Staging of disease was determined according to the American Joint Committee on Cancer staging system, 7th edition, 2010 (10). Lymph node status was determined in the patients by either sentinel lymph node (SLN) biopsy or lymph node dissection. Patients with 
pathologically positive SLN underwent a complete lymphadenectomy. Patients were treated and followed-up according to standard guidelines. Age of patients was classified as young ( $<40$ years), middle-aged (40-59 years) and old ( $\geq 60$ years). The present study was assessed and approved by the Ethics Committee of the Institute of Oncology, Istanbul University.

Statistical analysis. Data were presented as the number and percent of patients. Statistical analyses were performed using SPSS 21.0 software (IBM Corp., Armonk, NY USA). Comparisons between various clinicopathological factors and age of patients were performed using chi-square tests. Kaplan-Meier analysis was used for estimation of outcome of patients and differences in survival rates were assessed by log-rank statistics. Univariate and multivariate analyses were performed using Cox proportional hazards models. $\mathrm{P} \leq 0.05$ was considered to indicate a statistically significant difference.

\section{Results}

Patient characteristics. A total of 1,169 patients with cutaneous melanoma were enrolled into the present study. The median age of patients was 51 years, ranging from 16-104 years. Other demographical and clinicopathological characteristics are demonstrated in Table I. The majority of patients were middle-aged $(n=513 ; 43.9 \%)$, followed by old $(n=359 ; 30.7 \%)$ and young patients $(\mathrm{n}=297 ; 25.4 \%$; Table I). Although no significant sex differences were demonstrated in the young and old patients, middle-aged patients were significantly more male than female ( 60 vs. $40 \%$, respectively; $\mathrm{P}=0.001$ ). Non-superficial spreading histology was significantly more observed in old patients than other ages (63.4 vs. 45.9\%; $\mathrm{P}<0.001)$. It was demonstrated that a lower Clark invasion level was present in the young patients compared with middle-aged and old patients ( 38.8 vs. $29.8 \%$, respectively; $\mathrm{P}=0.013$ ) and higher levels were associated with older age compared with the young and middle-aged patients (75.1 vs. $64.8 \%$, respectively; $\mathrm{P}=0.002$ ). Furthermore, the rate of thin Breslow depth was higher in young patients compared with the other ages (41.3 vs. $33.5 \%$, respectively; $\mathrm{P}=0.038$ ). Although a lower mitotic rate was observed mainly in young patients compared with the other age groups (66.2 vs. $55.0 \%$, respectively; $\mathrm{P}=0.007)$, the presence of ulceration was significantly greater in old patients than of other ages (67.1 vs. $48.6 \%$, respectively; $\mathrm{P}<0.001)$. The absence of ulceration was significantly greater in young patients than of other ages (54.9 vs. $42.7 \%$, respectively; $\mathrm{P}=0.003)$.

However, age of patient was not significantly associated with other prognostic variables including anatomic localization, tumor infiltrating lymphocyte (TIL), neurotropism, regression, vertical growth phase, lymphovascular invasion and BRAF analysis. Furthermore, lymph node involvement, recurrence and metastasis of disease were not associated with the age of patient.

Effects of clinicopathological factors on relapse-free survival (RFS) and overall survival (OS). When univariate analyses of the effects of clinicopathological variables on RFS and OS were performed, patients with male gender, non-superficial spreading histology, nodular pathology, advanced Clark invasion level, thick Breslow depth, high mitotic rate, presence of ulceration, presence of lymphovascular invasion, presence of neurotropism, vertical growth phase, lymph node involvement and multiple node involvement were significant predictors of poor prognosis for both RFS and OS (all $\mathrm{P}<0.05$ ). Furthermore, recurrence of disease and distant metastasis were also significantly associated with OS (both $\mathrm{P}<0.001$ ). Contrastingly, other factors, including tumor localization, TIL, regression and BRAF analysis were not significantly associated with RFS or OS. Furthermore, it was demonstrated that age of patients was not significantly associated with RFS $(\mathrm{P}=0.327)$; however, age was significantly associated with $\mathrm{OS}$ ( $\mathrm{P}=0.007$; Table II; Figs. 1 and 2). Old patients had significantly poorer OS compared with the young $(\mathrm{P}=0.009)$ middle-aged $(\mathrm{P}=0.012)$ groups.

For multivariate analyses (data not shown) only mitotic rate $(\mathrm{P}=0.025)$ and lymph node involvement $(\mathrm{P}<0.001)$ retained their significances for RFS. However, the age of the patients was not independently associated with RFS $(\mathrm{P}=0.602)$. Similarly, age of patients did not remain significant for $\mathrm{OS}(\mathrm{P}=0.768)$, contrary to other prognostic factors, including lymph node metastasis $(\mathrm{P}=0.037)$, recurrence of disease $(\mathrm{P}<0.001)$ and metastatic disease $(\mathrm{P}<0.001)$.

\section{Discussion}

The present single institutional study investigated the prognostic significance and survival with clinicopathological factors in patients with all stages of melanoma for a full range of patient age groups. It was demonstrated that several poor prognostic factors of primary melanomas, including non-superficial spreading histology, higher Clark invasion and presence of ulceration, were significantly more observed in older patients than those other age groups, whereas, favorable features of a lower Clark invasion level, thin Breslow depth, lower mitotic rate and absence of ulceration were associated with younger patients. However, age was not a significant predictive factor of lymph node involvement among all stages of melanoma; no difference was demonstrated in the incidence of nodal metastasis in all age groups. On the other hand, patient age was significantly associated with survival; old patients had poorer survival compared with the other age groups.

Various melanoma studies have demonstrated that patient age is an independent prognostic factor for survival (3-6). It has been established in patients with early stage primary melanoma that older patients have more unfavorable clinicopathological features, such as the melanoma is thicker, ulcerated and has a higher mitotic rate (3-6). A large analysis of 17,600 patients with melanoma demonstrated that older patients had more advanced primary tumors, and that older age was correlated with lower melanoma survival (3). In another large multi-institutional study, consisting of 10,233 patients with localized tumors and 775 patients with nodal metastases, patients younger than 20 years old had melanomas with slightly more aggressive features yet, paradoxically, a more favorable survival outcome compared with all other age groups (4). Conversely, patients older than 70 years had melanomas with the most aggressive prognostic features, including head and neck localization, with thicker and more ulcerated melanomas and a greater mitotic rate, 


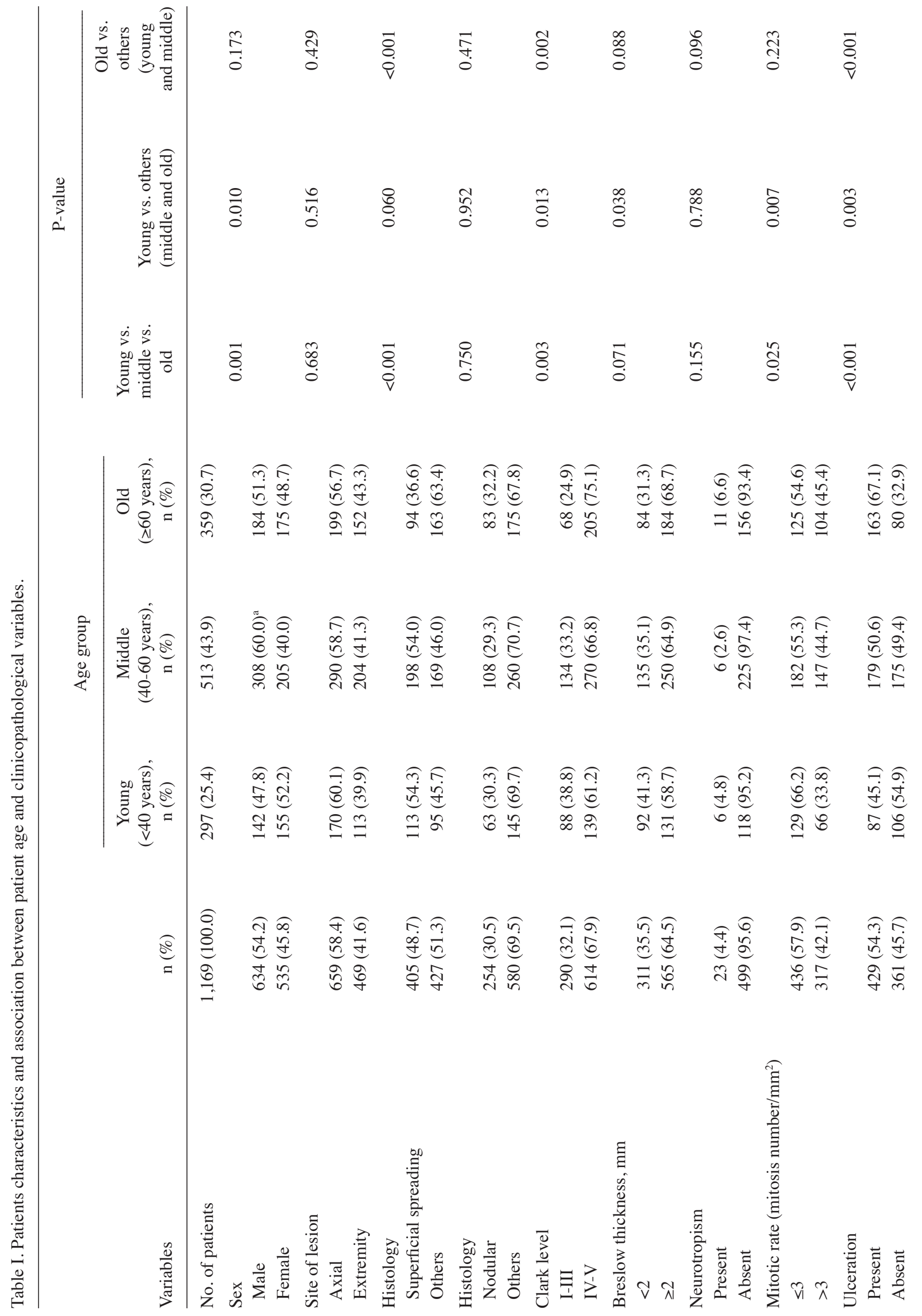




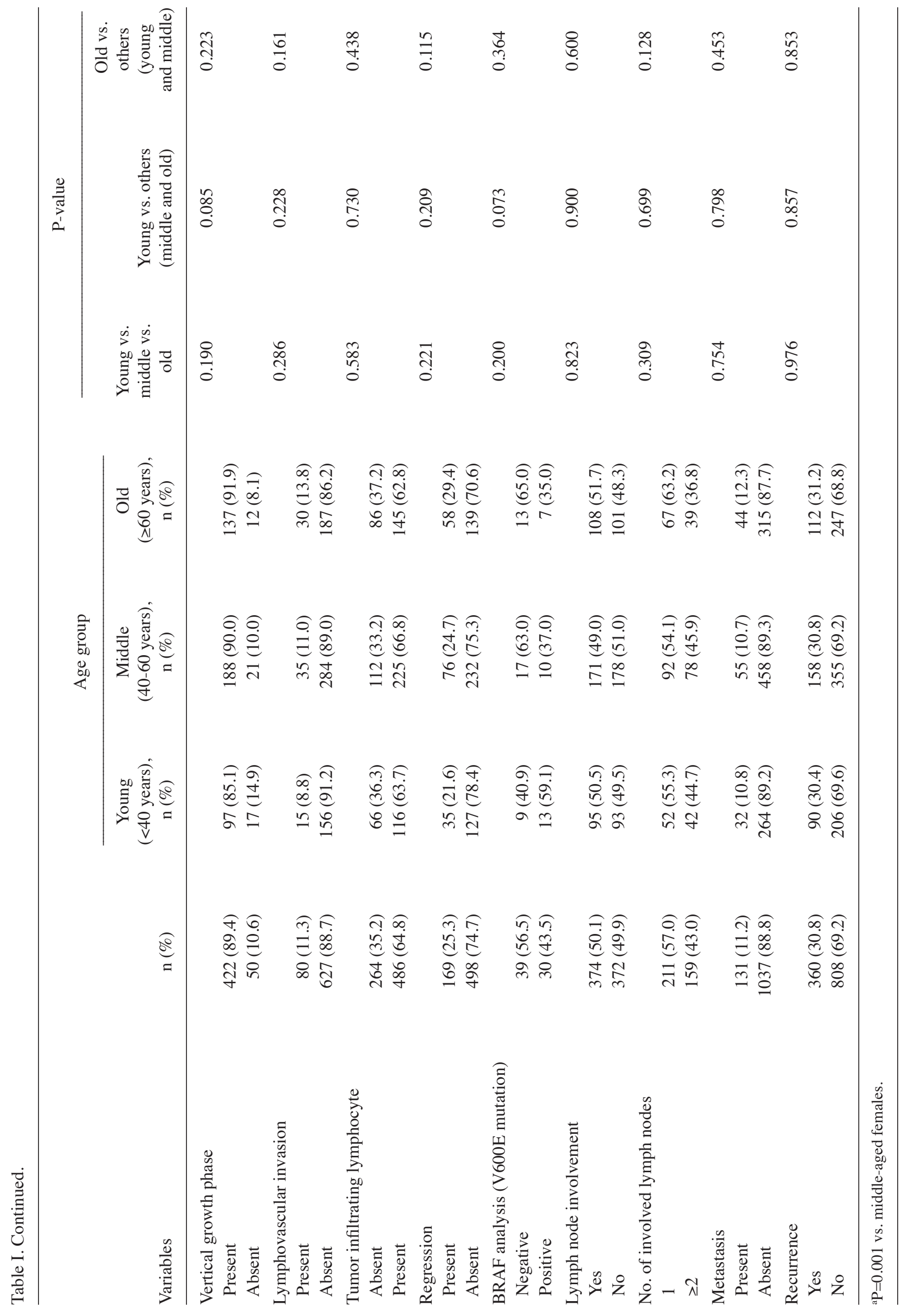


Table II. Univariate analyses of variables associated with RFS and OS.

\begin{tabular}{|c|c|c|}
\hline Variable & RFS P-value & OS P-value \\
\hline Sex (male vs. female) & $<0.001$ & $<0.001$ \\
\hline Site of lesion (axial vs. extremity) & 0.537 & 0.471 \\
\hline Histology (superficial spreading vs. others) & $<0.001$ & $<0.001$ \\
\hline Histology (nodular vs. others) & $<0.001$ & $<0.001$ \\
\hline Clark level (I-III vs. IV-V) & $<0.001$ & $<0.001$ \\
\hline Breslow thickness ( $<2$ vs. $\geq 2 \mathrm{~mm})$ & $<0.001$ & $<0.001$ \\
\hline Ulceration (present vs. absent) & $<0.001$ & $<0.001$ \\
\hline Mitotic rate ( $\leq 3$ vs. $>3$ mitosis number $/ \mathrm{mm}^{2}$ ) & $<0.001$ & $<0.001$ \\
\hline Lymphovascular invasion (present vs. absent) & $<0.001$ & $<0.001$ \\
\hline Regression (present vs. absent) & 0.088 & 0.113 \\
\hline Vertical growth phase (present vs. absent) & 0.009 & 0.012 \\
\hline Neurotropism (present vs. absent) & 0.052 & $<0.001$ \\
\hline Tumor infiltrating lymphocyte (present vs. absent) & 0.151 & 0.447 \\
\hline BRAF analysis (V600E mutation; positive vs. negative) & 0.508 & 0.825 \\
\hline Lymph node involvement (yes vs. no) & $<0.001$ & $<0.001$ \\
\hline No. of involved lymph nodes (1 vs. $\geq 2$ ) & 0.054 & 0.033 \\
\hline Metastasis (yes vs. no) & - & $<0.001$ \\
\hline Recurrence (present vs. absent) & - & $<0.001$ \\
\hline \multicolumn{3}{|l|}{ Age, years } \\
\hline$<40$ vs. $40-60$ vs. $\geq 60$ & 0.327 & 0.007 \\
\hline$<40$ vs. $40-60$ & 0.913 & 0.634 \\
\hline$<40$ vs. $\geq 60$ & 0.326 & 0.009 \\
\hline $40-60$ vs. $\geq 60$ & 0.27 & 0.012 \\
\hline
\end{tabular}

RFS, relapse-free survival; OS, overall survival.

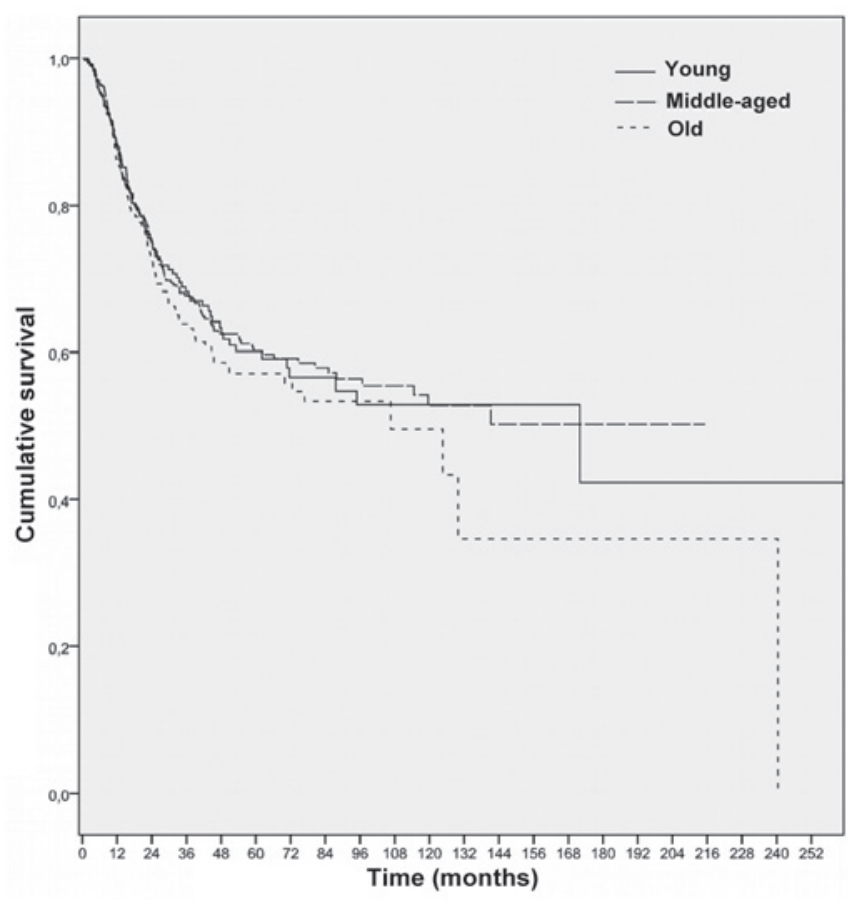

Figure 1. Relapse-free survival curves in patients with melanoma according to age (young vs. middle-aged vs. old age, $\mathrm{P}=0.327$; young vs. middle-aged, $\mathrm{P}=0.913$; young vs. old age, $\mathrm{P}=0.326$; and middle-aged vs. old age, $\mathrm{P}=0.270$ ).

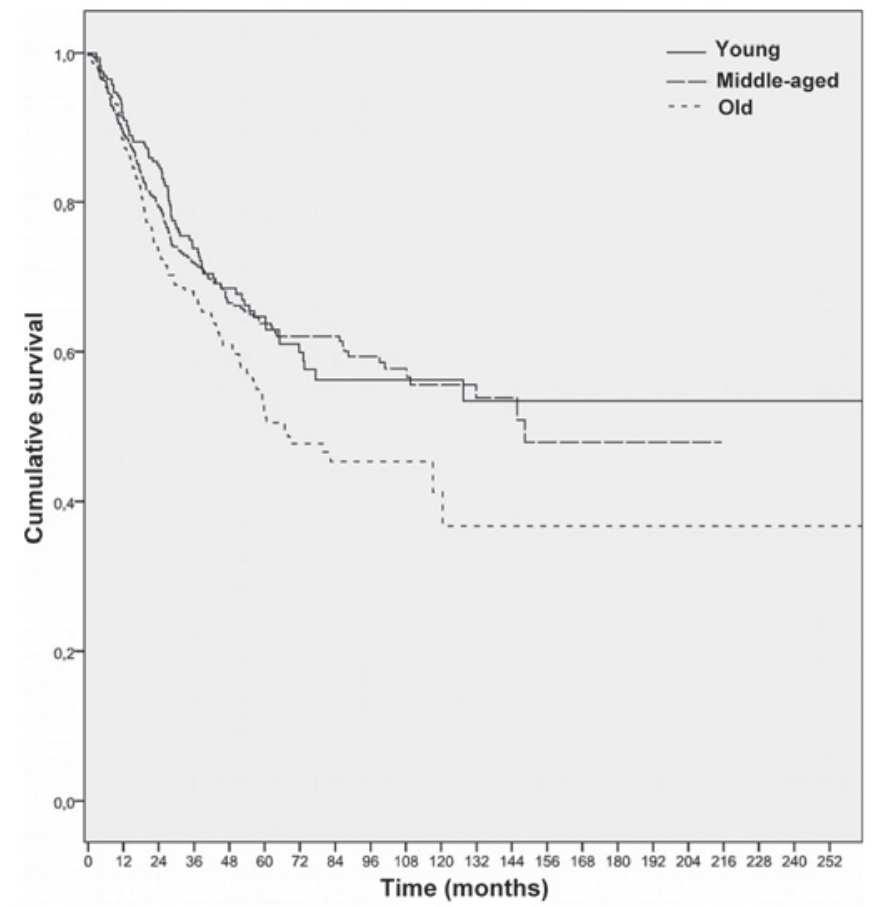

Figure 2. Overall survival curves in patients with melanoma according to age (young vs. middle-aged vs. old age, $\mathrm{P}=0.007$; young vs. middle-aged, $\mathrm{P}=0.634$; young vs. old age, $\mathrm{P}=0.009$; and middle-aged vs. old age, $\mathrm{P}=0.012$ ). 
although they had a lower rate of lymph node involvement (4). Additionally, patients between 20-70 years of age had few noticeable differences in the natural history or survival rates (4). This suggests that melanomas at the extremes of age have a distinct natural history. These issues were important to permit tailoring of therapy to match the biology of each patient by the authors. Conversely, in a single institutional trial, 849 patients with stage III melanoma were investigated to analyze the characteristics and outcomes in patients older than 65 years of age (5). The older 225 patients had higher primary tumor stage, higher Breslow thicknesses and ulceration, and poorer survival than younger patients.

It has been observed that with increasing age, factors of primary melanoma become more advanced and poorer histological features, are thicker, with higher mitotic rates, and are more likely to be ulcerated (3-6). In light of these data, it has been hypothesized that older patients with clinically localized melanoma may have higher incidence of nodal involvement, possibly explaining why they had poorer survival rates. In literature, unexpected findings have been observed; these older patients had a lower rate of lymph node metastasis (4,6-9). The expanded American Joint Committee on Cancer Melanoma Staging Database contained a cohort of 7,756 patients with stage I and II melanoma, and a significant decrease in the incidence of node metastasis was observed as patient age increased (6). The highest incidence of node metastasis was $25.8 \%$ in patients under 20 years of age, followed by $20 \%$ in those aged 20-40 years and $15.5 \%$ in patients older than 80 years (6). Conversely, in concordance with literature, older patients had more aggressive histological features and a higher mortality rate compared to all other age groups (3-5). Patient age was found to be a statistically significant independent predictor of sentinel node metastasis in a previous study (6). Thus, it may be recommended that this could be a bias to use the sentinel node biopsy more conservatively and less frequently in older patients compared with other patients in different age groups.

The causes of the heterogeneity of primary melanoma and the diversity of outcomes of the primary melanomas in the young and elderly population have not been clearly defined. However, there are some possible explanations, such as recognized decrease in immune competence with advancing age, lack of effectiveness of health education, screening procedures, difficulties in identifying and interpretation of pigmented lesions in elderly people, increasing hematogenous route of metastases, or reduction and atrophy of the dermal lymphatic vessels in older patients in consequence of age-related changes in lymphatic function $(5,6)$.

In conclusion, the present study demonstrated a significant heterogeneity of primary melanoma and the diversity of survival among patients with melanoma; elderly patients with melanoma were associated with more aggressive histological features and a higher mortality rate compared to all other age groups, irrespective of nodal involvement. Thus, early diagnosis of primary lesions in elderly patients should be critical and as important as early diagnosis in younger subjects.

\section{References}

1. Siegel RL, Miller KD and Jemal A: Cancer Statistics, 2017. Ca Cancer J Clin 67: 7-30, 2017.

2. Balch CM, Gershenwald JE, Soong SJ, Thompson JF, Atkins MB, Byrd DR, Buzaid AC, Cochran AJ, Coit DG, Ding S, et al: Final version of 2009 AJCC melanoma staging and classification. J Clin Oncol 27: 6199-6206, 2009.

3. Balch CM, Soong SJ, Gershenwald JE, Thompson JF, Reintgen DS, Cascinelli N, Urist M, McMasters KM, Ross MI, Kirkwood JM, et al: Prognostic factors analysis of 17,600 melanoma patients: Validation of the American Joint Committee on Cancer melanoma staging system. J Clin Oncol 19: 3622-3634, 2001.

4. Balch CM, Soong SJ, Gershenwald E, Thompson JF, Coit DG, Atkins MB, Ding S, Cochran AJ, Eggermont AM, Flaherty KT, et al: Age as a prognostic factor in patients with localized melanoma and regional metastases. Ann Surg Oncol 20: 3961-3968, 2013.

5. Rutkowski P, Nowecki ZI, Zdzienicki M, Michej W, Symonides M, Rosinska M, Dziewirski W, Bylina E and Ruka W: Cutaneous melanoma with nodal metastases in elderly people. Int J Dermatol 49: 907-913, 2010.

6. Balch CM, Thompson JF, Gershenwald JE, Soong SJ, Ding S, McMasters KM, Coit DG, Eggermont AM, Gimotty PA, Johnson TM, et al: Age as a predictor of sentinel node metastasis among patients with localized melanoma: An inverse correlation of melanoma mortality and incidence of sentinel node metastasis among young and old patients. Ann Surg Oncol 21: 1075-1081, 2014.

7. McMasters KM, Wong SL, Edwards MJ, Ross MI, Chao C, Noyes RD, Viar V, Cerrito PB and Reintgen DS: Factors that predict the presence of sentinel lymph node metastasis in patients with melanoma. Surgery 130: 151-156, 2001.

8. Chao C, Martin RC II, Ross MI, Reintgen DS, Edwards MJ, Noyes RD, Hagendoorn LJ, Stromberg AJ and McMasters KM: Correlation between prognostic factors and increasing age in melanoma. Ann Surg Oncol 11: 259-264, 2004.

9. Sondak VK, Taylor JM, Sabel MS, Wang Y, Lowe L, Grover AC, Chang AE, Yahanda AM, Moon J and Johnson TM: Mitotic rate and younger age are predictors of sentinel lymph node positivity: Lessons learned from the generation of a probabilistic model. Ann Surg Oncol 11: 247-258, 2004.

10. Edge SB, Byrd DR, Compton CC, Fritz AG, Greene FL and Trotti A (eds): AJCC cancer staging manual (7th edition). Springer, New York, NY, 2010. 